\title{
Intimate Partner Violence and Cancer Screening among Urban Minority Women
}

\author{
Sheetal Gandhi, BS, Sue Rovi, PhD, Marielos Vega, BSN, RN, \\ Mark S. Johnson, MD, MPH, Jeanne Ferrante, MD, MPH, and Ping-Hsin Chen, PhD
}

Purpose: To evaluate the association of intimate partner violence (IPV) with breast and cervical cancer screening rates.

Methods: We conducted retrospective chart audits of 382 adult women at 4 urban family medicine practices. Inclusion criteria were not being pregnant, no cancer history, and having a partner. Victims were defined as those who screened positive on at least one of 2 brief IPV screening tools: the HITS (Hurt, Insult, Threat, Scream) tool or Women Abuse Screening Tool (short). Logistic regression models were used to examine whether nonvictims, victims of emotional abuse, and victims of physical and/or sexual abuse were up to date for mammograms and Papanicolaou smears.

Results: Prevalence of IPV was 16.5\%. Compared with victims of emotional abuse only, victims of physical and/or sexual abuse aged 40 to 74 were associated with $87 \%$ decreased odds of being up to date on Papanicolaou smears (odds ratio, 0.13; 95\% CI, 0.02- 0.86) and 84\% decreased odds of being up to date in mammography (odds ratio, 0.16 ; 95\% CI, 0.03-0.99). There was no difference in Papanicolaou smear rates among female victims and nonvictims younger than 40 .

Conclusions: Because of the high prevalence of IPV, screening is essential among all women. Clinicians should ensure that victims of physical and/or sexual abuse are screened for cervical cancer and breast cancer, particularly women aged 40 or older. Cancer screening promotion programs are needed for victims of abuse. (J Am Board Fam Med 2010;23:343-353.)

Keywords: Domestic Violence, Cancer Screening, Intimate Partner Violence

Intimate partner violence (IPV) is an important social concern. It is estimated that 7.7 million IPV victimizations occur each year and that the lifetime prevalence of IPV victimization is $25 \%$ among women and $8 \%$ among men in the general population. ${ }^{1}$ Women are particularly vulnerable to the harmful effects of IPV; they are 7 to 14 times more

\footnotetext{
This article was externally peer reviewed.

Submitted 20 May 2009; revised 22 October 2009; accepted 2 November 2009.

From the Department of Family Medicine, University of Medicine and Dentistry of New Jersey-New Jersey Medical School, Newark (SG, SR, MV, MSJ, JF, P-HC); the University of Medicine and Dentistry of New Jersey-Robert Wood Johnson Medical School, New Brunswick (JF); and the Cancer Institute of New Jersey, New Brunswick (JF).

Funding: The study was funded in part by the American Academy of Family Physicians Foundation (\#G0415) and by a Summer Student Research Program from the University of Medicine and Dentistry of New Jersey-New Jersey Medical School.

Conflict of interest: none declared.

Corresponding author: Ping-Hsin Chen, $\mathrm{PhD}$, Department of Family Medicine, University of Medicine and Dentistry of New Jersey-New Jersey Medical School, BHSB E1557, 183 S. Orange Avenue, Newark, NJ 07103 (E-mail: chenpi@umdnj.edu).
}

likely than men to suffer severe physical injury from an assault by an intimate partner. ${ }^{2}$ A history of being the target of violence puts women at increased risk of physical injury, chronic pain syndromes, irritable bowel syndrome, gastrointestinal disorders, sexually transmitted diseases, ${ }^{3-5}$ depression, suicide attempts, psychosomatic disorders, reproductive health consequences, and other comorbidities. $^{6}$ Victims also reported more risky behaviors, including smoking, heavy drinking, and drug use. ${ }^{1,7-10}$

More recently, research has explored the association between IPV and health issues related to breast and cervical cancer. Studies have found that exposure to IPV increases the risk of cervical cancer, ${ }^{11,12}$ possibly through its effect on risk factors such as stress, smoking, and drinking. ${ }^{11}$ Alternatively, IPV may be related to decreased adherence to cancer screening. Findings from the few studies about the association between IPV and cancer screening have been inconsistent. A recent Australian study of 7312 middle-aged women (aged 45 to 50) found that those who have experienced IPV 
were less likely to engage in cervical cancer screening. ${ }^{13}$ In contrast, a smaller US study of women (aged 18 to 54) indicated that victims of physical or sexual abuse were more likely to have a Papanicolaou smear. ${ }^{14}$ Other studies have suggested no difference in cancer screening rates between victims of IPV and nonvictims. ${ }^{15-17}$ Using a populationbased health survey, one study indicated that victims of IPV receive Papanicolaou smears and clinical breast examinations at similar rates as other women. ${ }^{16}$ Another study examined 101 women with breast, cervical, endometrial, or ovarian cancer and found that IPV victims and nonvictims did not differ in rates of annual Papanicolaou tests or annual mammograms. ${ }^{17} \mathrm{~A}$ third study found that exposure to physical violence was not associated with cancer screening, although women with safety concerns were less likely to report cervical cancer testing and mammography. ${ }^{15}$

The studies above were conducted with mostly white women. There is little research regarding adherence to cancer screening among minority victims of IPV. Compared with white women, minority women have lower mammography screening rates. ${ }^{18}$ Physical health status, such as comorbidity and obesity, have been found to be barriers to cancer screening among minority women. ${ }^{19,20}$ However, the effect of social influences as barriers to cancer screening remains largely unexamined. Studies have suggested that IPV is a risk factor for medical noncompliance. ${ }^{18,21}$ African-American women reported IPV as a social issue that made preventive health care less of a priority for them. ${ }^{18}$

This study aims to add to the literature by using chart audit data to examine the relationship of IPV and cancer screening in a population of predominantly minority women. To our knowledge this is the first study using chart audits to examine cancer screening rates of victims of IPV and nonvictims. Previous studies have relied on self-reported data about cancer screening rates, which may be limited by accuracy of recall and social desirability bias. ${ }^{13,14,22-24}$ Chart audit data are preferable over self-report data when determining cancer screening rates because patient report often leads to high false-positive rates. ${ }^{25}$ Chart audits allowed us to take into account medical confounders of cancer screening that were not addressed in previous studies. We hypothesized that victims of IPV would have lower screening rates compared with nonvictims. In addition, we will add to the literature by examining nonlinear relations between IPV and cancer screening. We specifically explored the role of type of abuse and age in affecting cancer screening. The inconsistent findings from previous studies could suggest that nonlinear relationships exist between IPV and cancer screening. ${ }^{15}$ We hypothesized that types of abuse would affect cancer screening differently. Because middle-aged IPV victims (not younger populations) previously have been found to have lower rates of cervical cancer screening, ${ }^{13-17}$ we hypothesized that age interacts with IPV to affect cervical cancer screening rates.

\section{Methods}

This study was a cross-sectional, retrospective review of charts at 4 urban primary care settings: a university-based faculty practice, its communitybased residency practice, and 2 satellite faculty community practices. The 4 practices combined have 18 physicians and 27 residents who see approximately 3500 patients per month, of which $86 \%$ are African American or Hispanic. During July 2004 through June 2005, 523 female patients who were aged 18 or older and involved with a partner were recruited and screened for IPV at one of the 4 clinical settings. As described in a previous publication about this study, all participants agreed to have their medical records reviewed. ${ }^{26}$ Institutional review board approval for this study was obtained.

For the purpose of this study we used guidelines from the American Cancer Society in 2004 when patients were screened for IPV. ${ }^{27}$ Women aged 40 and older were included for breast cancer screening analysis. We used the criterion of age 21 and older for cervical cancer screening analysis. Because data about the onset of vaginal intercourse were not collected, the criterion of 3 years after onset of vaginal intercourse as the age to begin Papanicolaou smears was not used. Women aged 75 and older were excluded because they are less likely to experience IPV and recommendations of cancer screening tests are not universal in this age group. We excluded pregnant women and those with a history of any cancer; women who had hysterectomies were also excluded for cervical cancer screening analysis. Therefore, 382 women were included in the analytic sample. 


\section{Procedures}

Part-time data abstractors were hired to conduct the chart reviews. A chart abstraction form and codebook explaining explicit coding criteria were designed to increase standardization. Before the start of data abstraction the abstractors received 1 week of intensive training by 2 investigators (MV and PC). The training covered the computerized medical record system, a standardized method of chart review, and issues of confidentiality. The medical record was abstracted from computerized databases and/or paper charts from the practices. Information abstracted from the charts included demographics, social history, number of visits, documentation of IPV, and chronic medical conditions. Data were abstracted from all sections of the chart, including registration forms, problem lists, progress notes, laboratory tests, imaging studies, and data from various specialty clinics.

One investigator (MV) served as a gold standard for chart reviews. She abstracted $5 \%$ of charts $(20$ charts) and interrater reliability between the investigator and each abstractor was assessed on whether or not the patients were up to date with Papanicolaou smears and mammography by calculating the $\kappa$ statistic (Papanicolaou smears, $\kappa=0.79$; mammogram, $\kappa=0.92)$.

\section{Outcome Measures}

Using guidelines from the American Cancer Society, patients were considered up to date with cervical cancer screening if there was a Papanicolaou smear report dated within 3 years before the visit during which the patient was screened for IPV; they were considered up to date with breast cancer screening if a mammogram report was dated within 1 year before the IPV screening visit. ${ }^{27}$

\section{Main Independent Measures}

Participants were screened for IPV using 2 brief screening tools: the HITS (Hurt, Insult, Threat, Scream) tool or the Women Abuse Screening Tool (short version; WAST-Short). HITS comprises the following 4 items: (1) How often does your partner physically hurt you? (2) How often does your partner insult you or talk down to you? (3) How often does your partner threaten you with harm? and (4) How often does your partner scream or curse at you? Participants answered each question using a 5 -point scale ranging from "never" (1) to "frequently" (5). Answers were summed to form a total
HITS score, which could range from 4 to 20 . HITS is one of the shortest screening tools, forms an easily remembered acronym, has been tested with diverse populations, and has been tested and used in family medicine practices. ${ }^{26,28,29}$ Using a cutoff score of 10.5 , Sherin et $\mathrm{al}^{30}$ found that HITS accurately classified $91 \%$ of nonvictims and $96 \%$ of victims.

WAST-Short consists of 2 items from the 8 -item WAST $^{30}$ : (1) In general, how would you describe your relationship: a lot of tension, some tension, no tension? and (2) Do you and your partner work out arguments: with great difficulty, some difficulty, no difficulty? Women met the criteria for domestic violence exposure if they answered the questions with either "a lot of tension" or "great difficulty," respectively. To validate results from the IPV screening tool, the remaining 6 items of the WAST were asked in the questionnaire after screening. These items included, Do arguments ever result in you feeling down or bad about yourself? Do arguments ever result in hitting, kicking, or pushing? Do you ever feel frightened by what your partner says or does? Has your partner ever abused you physically? Has your partner ever abused you emotionally? and Has your partner ever abused you sexually? The WAST has a reliability of 0.75 , and abused women identified by the WASTShort scored significantly higher on WAST than did women who were not abused. ${ }^{30}$

We used a 2-step approach to determine victims of emotional, physical, and/or sexual abuse. First, women who screened positive on HITS tool or the WAST-Short were defined as victims. Second, victims who reported emotional abuse and no physical or sexual abuse on the HITS tool or the WAST were classified as victims of emotional abuse only. Those who reported physical abuse on the HITS tool or the WAST were classified as victims of physical abuse. Identified victims who reported the one item on the WAST about sexual abuse were classified as victims of sexual abuse. ${ }^{30}$ Because our sample size of women who experienced sexual abuse was small ( $\mathrm{n}=5$ for ages 21 to 39 and $\mathrm{n}=2$ for ages 40 to 74 ) and all victims of sexual abuse also reported physical abuse, we combined physical and sexual abuse in our analysis.

\section{Potential Confounders}

Known risk factors for IPV, cervical cancer, and breast cancer (based on the literature) were selected 
as potential confounders for the adjusted models. ${ }^{1,7-11,13,15,19,20,29,31}$ Demographic factors included age (21 to 29 years, 40 to 49 years, 50 to 64 years, and 65 to 74 years); race/ethnicity (white, African American, Hispanic, other); education level ( $\leq$ high school, some college, college completed); employment status (employed or unemployed); insurance type (commercial, Medicaid/Medicare, other); and marital status (married or unmarried). Health risk behavior included smoking status (ever a smoker or never a smoker); drug use within the past year (yes or no); and alcohol use within the past year (yes or no). Health care utilization was measured by the number of visits to any physician during the past year ( $<2$ times, 3 to 5 times, $>5$ times). Practice locations included 3 faculty practices and a residency program.

Measures of health status included family history of breast cancer (yes or no), family history of cervical cancer (yes or no), obesity, and comorbidity. Obesity was measured by body mass index (BMI). Underweight/normal weight was defined as a BMI $<25$. Those who had a BMI between 25 and 29 were considered overweight. Obesity was defined as a $\mathrm{BMI} \geq 30$. We used the Charlson comorbidity index to measure comorbidity. ${ }^{32,33}$ This is a weighted index of 19 disease categories that have been found to be related to mortality. Charlson comorbid conditions (and their corresponding weightings) include myocardial infarction (1), congestive heart failure (1), peripheral vascular disease (1), cerebrovascular disease (1), dementia (1), chronic pulmonary disease (1), connective tissue disease (1), ulcer disease (1), mild liver disease (1), diabetes without complications (1), diabetes with complications (2), hemiplegia (2), renal disease (2), any tumor without metastases (2), leukemia (2), lymphoma (2), moderate or severe liver disease (3), metastatic solid tumor (6), and acquired immunodeficiency syndrome (6). Increasing scores on the Charlson comorbidity index reflect an increasing burden (in number and severity) of comorbid conditions.

\section{Data Analysis}

We performed analyses using SPSS (version 15.0 for Windows; SPSS Inc., Chicago, IL). $\chi^{2}$ tests were used to compare sample characteristics, identify predictors of cancer screening, and examine associations between IPV and cancer screening. Sample characteristics, sociodemographic back- ground, health behaviors, family history of cancer, health status, and practice location were compared among nonvictims, victims of emotional abuse only, and victims of physical and/or sexual abuse. We then identified confounders among the sample characteristics of being up to date with breast and cervical cancer screening. Finally, we conducted multivariate analysis to control for the potential confounders based on stratified analysis of age. Separate logistic regression models were created for mammograms and Papanicolaou smears among women. For Papanicolaou smears, we performed stratified analysis to test whether relationships with IPV and screening practices were different according to age (21 to 39 years vs 40 to 74 years). For each outcome, we first compared nonvictims (reference group) with victims of emotional abuse only and victims of physical and/or sexual abuse, respectively. We then built additional models to compare victims of emotional abuse only (reference group) and victims of physical and/or sexual abuse. Decision about the inclusion of confounders in each model was based on the results of bivariate analysis. Variables significantly associated with each outcome and IPV at the $P<.05$ level were noted for greater parsimony. ${ }^{11,19} \mathrm{We}$ did not include any practice-level variables to control for clustering effect because detailed information about the practices was not collected. In addition, the small group size of the residency practice $(n<50)$ and its lack of variation on victim status may generate biased estimates when conducting multilevel analysis. ${ }^{34}$ Adjusted odds ratios and $95 \%$ confidence intervals were computed.

\section{Results \\ Participants}

Table 1 summarizes the sample characteristics of nonvictims, victims of emotional abuse only, and victims of physical and/or sexual abuse. Of the 382 participants, the majority of women were younger than 40 years, African American, and unmarried. Overall, $16.5 \%$ were victims of IPV. The majority of victims (58.5\%) reported emotional abuse only; $41.5 \%$ of victims reported physical and/or sexual abuse. Victims of IPV and nonvictims were similar in sociodemographic background, health behaviors, family history of cancer, number of visits, and health status. Compared with nonvictims and victims of emotional abuse, victims of physical and/or 
Table 1. Sample Characteristics by Type of Domestic Violence

\begin{tabular}{|c|c|c|c|c|c|}
\hline Characteristics & $\begin{array}{l}\text { Total (\%) } \\
(\mathrm{n}=382)\end{array}$ & $\begin{array}{l}\text { Nonvictims (\%) } \\
\quad(\mathrm{n}=319)\end{array}$ & $\begin{array}{l}\text { Victims of Emotional } \\
\text { Abuse Only (\%) } \\
(\mathrm{n}=37)\end{array}$ & $\begin{array}{c}\text { Victims of Physical and/or } \\
\text { Sexual Abuse }(\%) \\
(\mathrm{n}=26)\end{array}$ & $P^{\dagger}$ \\
\hline Age (years) & & & & & .540 \\
\hline $21-29$ & 32.8 & 33.0 & 35.1 & 26.9 & \\
\hline $30-39$ & 30.2 & 30.8 & 29.8 & 23.1 & \\
\hline $40-49$ & 22.6 & 23.0 & 13.5 & 30.8 & \\
\hline $50-74$ & 14.4 & 13.2 & 21.6 & 19.2 & \\
\hline Race/ethnicity & & & & & .666 \\
\hline White & 9.4 & 10.0 & 5.4 & 7.7 & \\
\hline African American & 77.0 & 76.5 & 83.8 & 73.1 & \\
\hline Hispanic & 9.4 & 8.8 & 10.8 & 15.4 & \\
\hline Other & 4.2 & 4.7 & $0^{*}$ & $3.8^{*}$ & \\
\hline Educational level completed & & & & & .131 \\
\hline$\leq$ High school & 43.0 & 40.3 & 59.5 & 53.8 & \\
\hline Some college & 35.2 & 36.5 & 24.3 & 34.6 & \\
\hline College completed & 21.8 & 23.3 & 16.2 & 11.5 & \\
\hline Employment & & & & & .050 \\
\hline Employed & 73.9 & 75.7 & 73.0 & 53.8 & \\
\hline Unemployed & 26.1 & 24.3 & 27.0 & 46.2 & \\
\hline Insurance & & & & & .010 \\
\hline Commercial & 38.8 & 41.2 & 35.1 & 15.4 & \\
\hline Medicaid/Medicare & 54.1 & 50.6 & 62.2 & 84.6 & \\
\hline Other & 7.1 & 8.2 & 2.7 & 0 & \\
\hline Marital status & & & & & .767 \\
\hline Married & 35.7 & 35.2 & 35.1 & 42.3 & \\
\hline Unmarried & 64.3 & 64.8 & 64.9 & 57.7 & \\
\hline Smoking status & & & & & .520 \\
\hline Ever a smoker & 44.3 & 43.0 & 48.4 & 55.0 & \\
\hline Never a smoker & 55.7 & 57.0 & 51.6 & 45.0 & \\
\hline Drug use within the past year & & & & & .172 \\
\hline Yes & 23.6 & 22.3 & 24.3 & 38.5 & \\
\hline No & 76.4 & 77.7 & 75.7 & 61.5 & \\
\hline Alcohol use within the past year & & & & & .578 \\
\hline Yes & 23.3 & 24.1 & 21.6 & 15.4 & \\
\hline No & 76.7 & 75.9 & 78.4 & 84.6 & \\
\hline Family history of breast cancer & & & & & .037 \\
\hline Yes & 14.1 & 12.2 & 27.0 & 19.2 & \\
\hline No & 85.9 & 87.8 & 73.0 & 80.8 & \\
\hline Family history of cervical cancer & & & & & .302 \\
\hline Yes & 1.0 & 0.9 & $0^{*}$ & $3.8^{*}$ & \\
\hline No & 99.0 & 99.1 & 100.0 & 96.2 & \\
\hline Physician visits during the past year (n) & & & & & .020 \\
\hline$<2$ & 30.3 & 32.2 & 27.0 & 11.5 & \\
\hline $3-5$ & 46.8 & 47.6 & 43.2 & 42.3 & \\
\hline$>5$ & 22.9 & 20.2 & 29.7 & 46.2 & \\
\hline Body mass index & & & & & .332 \\
\hline Underweight/normal weight & 17.4 & 17.1 & 23.5 & 12.5 & \\
\hline Overweight & 27.7 & 26.6 & 38.2 & 25.0 & \\
\hline Obese & 54.8 & 56.3 & 38.2 & 62.5 & \\
\hline
\end{tabular}




\begin{tabular}{|c|c|c|c|c|c|}
\hline Characteristics & $\begin{array}{l}\text { Total }(\%) \\
(\mathrm{n}=382)\end{array}$ & $\begin{array}{l}\text { Nonvictims (\%) } \\
\quad(\mathrm{n}=319)\end{array}$ & $\begin{array}{l}\text { Victims of Emotional } \\
\text { Abuse Only (\%) } \\
(\mathrm{n}=37)\end{array}$ & $\begin{array}{c}\text { Victims of Physical and/or } \\
\text { Sexual Abuse }(\%) \\
(\mathrm{n}=26)\end{array}$ & $P^{\dagger}$ \\
\hline Comorbidity & & & & & .726 \\
\hline 0 & 62.6 & 63.0 & 62.2 & 57.7 & \\
\hline 1 & 24.3 & 23.8 & 29.7 & 23.1 & \\
\hline$\geq 2$ & 13.1 & 13.2 & 8.1 & 19.2 & \\
\hline \multicolumn{6}{|l|}{ Practice location } \\
\hline Faculty practice A & 58.4 & 57.1 & 70.3 & 57.7 & .690 \\
\hline Faculty practice B & 16.2 & 16.3 & 13.5 & 19.2 & \\
\hline Faculty practice $\mathrm{C}$ & 16.0 & 16.3 & 10.8 & 19.2 & \\
\hline Residency & 9.4 & 10.3 & 5.4 & 3.8 & \\
\hline
\end{tabular}

${ }^{*} \mathrm{n} \leq 1$.

${ }^{+}$Significance levels using $\chi^{2}$ test.

sexual abuse were more likely to be unemployed $(P=.05)$, insured by Medicaid $(P=.01)$, and have $>5$ office visits $(P=.02)$. Those who reported emotional abuse only had the highest prevalence of a family history of breast cancer among the 3 groups $(P=.037)$.

\section{Association of Patient Characteristics with Being $U$ p to Date with Cancer Screening}

Table 2 presents the proportion of women who were up to date with breast or cervical cancer screening based on sample characteristics. Among women aged 40 and older, $34.5 \%$ were up to date with mammograms and $49.6 \%$ were up to date with Papanicolaou smears. Among women aged 21 to 40 years, $60.9 \%$ were up to date with Papanicolaou smears.

Being up to date with mammograms was not associated with any patient characteristic. Being up to date with Papanicolaou smears was associated with insurance, marital status, number of visits, and practice location. Women with "other" insurance were less likely to get cervical cancer screening than those with commercial or Medicaid/ Medicare insurance (40.7\%, 51.4\%, and $62.6 \%$, respectively; $P=.027)$. Married women had a lower cervical cancer screening rate than unmarried women $(49.6 \%$ vs $61.0 \% ; P=$ .023). Those who had more visits were more likely to be up to date with Papanicolaou smears $(P=.05)$. Papanicolaou smear rates differed among practice locations $(P=.043)$.

\section{Prevalence of Being Up to Date with Cancer Screening by IPV Victim Status}

Table 3 shows prevalence of being up to date with cancer screening by IPV victim status. Among women aged 40 or older, those who reported physical and/or sexual abuse had lower breast cancer screening rates $(15.4 \%$ vs $53.8 \%)$ and cervical cancer screening rates $(36.4 \%$ vs $76.9 \%)$ than victims of emotional abuse. There was no statistically significant difference in cervical cancer screening rates among nonvictims, victims of emotional abuse only, and victims of physical and/or sexual abuse. Compared with victims of emotional abuse only, victims of physical and/or sexual abuse aged 40 to 74 years had $87 \%$ decreased odds of being up to date with Papanicolaou smears (odds ratio, 0.13; 95\% CI, $0.02-0.86$ ) and $84 \%$ decreased odds of being up to date in mammography (odds ratio, 0.16; 95\% CI, 0.03-0.99). There was no difference in Papanicolaou smear rates between victims and nonvictims among women younger than 40 years.

\section{Discussion}

To our knowledge this is the first study to examine the association between IPV and cancer screening rates based on chart reviews. Overall, 1 in 6 women reported IPV in their current intimate relationships, which is comparable to previous studies. $^{28,30,35}$ Our findings suggest that age interacts with IPV to affect cervical cancer screening rates. Victims and nonvictims did not differ in cervical cancer screening rates among women younger than 40 years. For middle-aged women, IPV-particularly physical and/or sexual abuse-was associated 


\begin{tabular}{|c|c|c|c|c|}
\hline \multirow[b]{2}{*}{ Characteristics } & \multicolumn{2}{|c|}{ Mammogram $(\mathrm{n}=142)$} & \multicolumn{2}{|c|}{$\begin{array}{l}\text { Papanicolaou Smear } \\
\qquad(\mathrm{n}=371)\end{array}$} \\
\hline & $\%$ & $P$ & $\%$ & $P$ \\
\hline Age & & .156 & & .103 \\
\hline 21-29 & N/A & & 63.2 & \\
\hline $30-39$ & N/A & & 58.4 & \\
\hline $40-49$ & 30.2 & & 52.4 & \\
\hline $50-74$ & 40.0 & & 44.0 & \\
\hline Race/ethnicity & & .998 & & .141 \\
\hline White & 35.7 & & 44.4 & \\
\hline African American & 34.2 & & 59.2 & \\
\hline Hispanic & 36.4 & & 60.0 & \\
\hline Other & 33.3 & & 37.5 & \\
\hline Educational level completed & & .786 & & .371 \\
\hline$\leq$ High school & 31.7 & & 57.9 & \\
\hline Some college & 38.0 & & 59.5 & \\
\hline College completed & 34.5 & & 50.0 & \\
\hline Employment & & .414 & & .541 \\
\hline Employed & 36.0 & & 56.8 & \\
\hline Unemployed & 32.7 & & 56.9 & \\
\hline Insurance & & .471 & & .027 \\
\hline Commercial & 40.0 & & 51.4 & \\
\hline Medicaid/Medicare & 31.1 & & 62.6 & \\
\hline Other & 25.0 & & 40.7 & \\
\hline Marital status & & .516 & & .023 \\
\hline Married & 35.0 & & 49.6 & \\
\hline Unmarried & 33.9 & & 61.0 & \\
\hline Smoking status & & .240 & & .505 \\
\hline Ever a smoker & 29.6 & & 61.1 & \\
\hline Never a smoker & 37.5 & & 61.7 & \\
\hline Drug use within the past year & & .469 & & .107 \\
\hline Yes & 36.7 & & 63.2 & \\
\hline No & 33.9 & & 54.9 & \\
\hline Alcohol use within the past year & & .477 & & .118 \\
\hline Yes & 36.4 & & 63.1 & \\
\hline No & 33.9 & & 55.1 & \\
\hline Family history of breast cancer & & .244 & & .130 \\
\hline Yes & 44.4 & & 64.8 & \\
\hline No & 33.1 & & 55.5 & \\
\hline Family history of cervical cancer & & .655 & & .421 \\
\hline Yes & $0^{*}$ & & 75.0 & \\
\hline No & 34.8 & & 56.7 & \\
\hline Physician visits during the past year (n) & & .943 & & .05 \\
\hline$<2$ & 32.4 & & 48.6 & \\
\hline $3-5$ & 35.6 & & 58.0 & \\
\hline$>5$ & 33.3 & & 65.9 & \\
\hline Body mass index & & .288 & & .626 \\
\hline Underweight/normal weight & 28.6 & & 55.4 & \\
\hline Overweight & 25.0 & & 55.1 & \\
\hline Obese & 40.0 & & 60.6 & \\
\hline
\end{tabular}




\begin{tabular}{|c|c|c|c|c|}
\hline \multirow[b]{2}{*}{ Characteristics } & \multicolumn{2}{|c|}{ Mammogram $(\mathrm{n}=142)$} & \multicolumn{2}{|c|}{$\begin{array}{l}\text { Papanicolaou Smear } \\
\qquad(\mathrm{n}=371)\end{array}$} \\
\hline & $\%$ & $P$ & $\%$ & $P$ \\
\hline Comorbidity & & .107 & & .517 \\
\hline 0 & 28.9 & & 54.7 & \\
\hline 1 & 48.6 & & 61.5 & \\
\hline$\geq 2$ & 31.0 & & 58.7 & \\
\hline Practice location & & .597 & & .043 \\
\hline Faculty practice A & 34.1 & & 55.8 & \\
\hline Faculty practice B & 26.9 & & 70.5 & \\
\hline Faculty practice $\mathrm{C}$ & 38.9 & & 41.7 & \\
\hline Residency & 50.0 & & 56.1 & \\
\hline
\end{tabular}

${ }^{*} \mathrm{n} \leq 1$.

with delays in breast and cervical cancer screenings. Other results from this study support previous literature that insurance, marital status, physician visits, and type of practice are associated with cancer screening. ${ }^{11,15,19,20}$

The majority of studies assume linear relationships between IPV and cancer screening rates. ${ }^{15-17}$ However, further exploration of our data suggests that nonlinear relationships may also exist. Breast and cervical cancer screening seem to follow different patterns according to age. Our finding is consistent with the growing literature that, among younger women, IPV victims do not report lower rates of Papanicolaou screening than nonvictims. ${ }^{14-17}$ Younger women might receive Papanicolaou screens when they visit their doctors for contraceptive and reproductive check-ups. ${ }^{13,20} \mathrm{Al}$ ternatively, it may be that younger women who experienced IPV were concerned about contracting sexually transmitted diseases, which increased their likelihood of getting pelvic exams and Papanicolaou smears.

For middle-aged women, the type of abuse plays an important role in affecting cancer screening rates. A recent study of middle-aged women indicated that those who were involved in a violent relationship reported lower rates of cervical cancer screening. ${ }^{13}$ We extend previous findings to demonstrate that physical and/or sexual abuse among middle-aged women was associated with delays in both breast and cervical cancer screening. Recent literature has suggested that high levels of IPV may

Table 3. Prevalence of Being Up to Date with Cancer Screening by Intimate Partner Violence Victim Status

\begin{tabular}{lccc}
\hline Prevalence & Mammogram, Ages $\geq 40^{*}$ & Papanicolaou Smear, Ages 21-39 & Papanicolaou Smear, Ages $\geq 40^{\ddagger}$ \\
\hline Prevalence (\%) & & & 49.6 \\
$\quad$ Total & 34.5 & 60.9 & 47.7 \\
$\quad$ Nonvictims & 34.5 & 58.2 & 76.9 \\
Emotional abuse only & 53.8 & 66.7 & 36.4 \\
Physical and/or sexual abuse & 15.4 & 92.3 & $3.81(0.96-15.20)$ \\
Adjusted odds ratio (CI) & & & $0.61(0.17-2.22)$ \\
Emotional abuse only & $2.74(0.81-9.25)$ & $6.21(0.76-51.01)$ & $0.16(0.03-0.99)$ \\
Physical and/or sexual abuse & $0.35(0.07-1.66)$ & $5.61(0.58-54.58)$ & \\
Physical and/or sexual abuse & $0.13(0.02-0.85)$ & &
\end{tabular}

*Based on logistic regression, controlling for education.

${ }^{\dagger}$ Based on logistic regression, controlling for insurance, family history of breast cancer, number of physician visits during the past year, and practice location.

${ }^{\ddagger}$ Based on logistic regression, controlling for education.

${ }^{\S}$ Reference group was nonvictims.

"Reference group was emotional abuse only. 
lead to decreased utilization of preventive services. ${ }^{15}$ Multiple competing demands faced by victims of physical and/or sexual abuse and their providers could be a major barrier to breast and cervical cancer screening. It is well documented that women experiencing severe IPV are at increased risk of physical and mental health problems and report more health risk behavior. ${ }^{6}$ These demands may increase acute and chronic care management of these women and make preventive services less of a priority. Alternatively, women experiencing severe abuse may be less likely to make appointments to receive preventive services because of the controlling behavior of the abusive partner. ${ }^{36}$ Victims of IPV may not want to get cervical cancer screening because they consider a pelvic examination to be invasive and traumatic. Papanicolaou smears have been found to be traumatic for women who reported sexual abuse. ${ }^{37}$ It is unclear why victims of emotional abuse had the highest rates of breast and cervical cancer screening, and future studies are needed to confirm this finding.

Our findings provide support that breast and cervical cancer screening rates among minority victims of IPV are far below the national averages. Data from the 2000 National Health Interview Survey indicated that mammogram screening rates were $72.1 \%$ and the rate of Papanicolaou smears was $84.9 \% .{ }^{19}$ Consistent with previous studies, our findings show that cancer screening rates among this underserved minority population were at least $20 \%$ lower than in the US adult population. ${ }^{20}$ Screening rates in the community are probably even less compared with those who were recruited when they came into the medical practices. Underserved minority women-especially those older than 40-who reported IPV may be particularly vulnerable to delayed cancer screening. In this study, cancer screening rates among victims of IPV were at least $15 \%$ lower than the average of this underserved minority population. Further studies are needed to compare cancer screening rates of IPV victims and nonvictims in various ethnic populations. Additional studies are also needed to investigate how IPV interactions with ethnic health disparities affect cancer screening.

There are several limitations in this study. First, the sample size was relatively small and resulted in large confidence intervals for some of our estimates. Larger-scale chart audits are needed to confirm differences in cancer screening among nonvic- tims and victims of various types of abuse. Second, IPV is likely underestimated or overestimated. Abused women may refuse to participate in the study, and victims may choose not to disclose their IPV status. Those who experienced sexual abuse only may not have been classified as victims based on the HITS screening tool and the WAST-Short. Only the full 8-item WAST asks about sexual abuse, but it is not used as a criterion to distinguish between victims and nonvictims. However, it is highly unlikely that some women are only sexually abused. In a previous study, all women who experienced sexual abuse within an IPV relationship also reported other forms of abuse. ${ }^{29}$ Another study found that $68 \%$ of women who are physically abused are also sexually assaulted. ${ }^{38}$ The chart review was performed with patients recruited for another IPV study, thus willingness to participate may overestimate the prevalence of IPV.

Chart reviews are limited by lack of documentation of certain measures, such as family history of cancer and incomplete problem lists. However, completeness of documentation should not differ between nonvictims and victims of IPV. We did not collect data about abnormal Papanicolaou smears or mammograms. If the patient did have a previously abnormal Papanicolaou smear or mammogram, the follow-up tests would no longer be used for screening but for diagnosis. Screening intervals may vary based on the detection of abnormalities. This should be considered in future work of this kind. We also did not record clinical breast exams. However, the US Preventive Services Task Force concluded in 2002 that the evidence was insufficient to recommend for or against routine clinical breast examination alone to screen for breast cancer. ${ }^{39}$ In addition, clinical breast exams are not always well documented in charts. Finally, this study was conducted with low-income, minority women who were receiving care in academic urban settings. Results of this study may not be generalized to other populations.

\section{Conclusion}

This study suggests that IPV is common in patients seen in medical practices and can be a barrier to cancer screening. The findings that breast and cervical cancer screening present different patterns according to the type of abuse underscore the need to screen for IPV and identify types of IPV. Several 
medical organizations have recommended that health care providers routinely screen for, recognize, and document IPV. ${ }^{40-42}$ Providers may consider using lower rates of breast or cervical cancer screening as a red flag to recognize IPV and vice versa.

This study identifies victims of IPV older than age 40 as a group at high risk for delays in cancer screening. Delays in cancer screening may lead to being diagnosed with cancer at more advanced stages. ${ }^{17,36}$ Avoidance of pelvic exams may lead to higher rates of undiagnosed sexually transmitted diseases such as human papillomavirus, which may lead to higher incidence of cervical cancer and later-stage diagnosis. A recent survey study found that IPV raises the risk of cervical cancer. ${ }^{11} \mathrm{Ob}-$ taining preventive care is essential to detect tumors early and provide appropriate and potentially lifesaving interventions. To ensure that victims of physical and/or sexual abuse are screened for cancer, further study is needed to determine how to make cancer screening more acceptable to this vulnerable group. In addition, cancer screening programs should continue to be promoted among underserved minorities.

The authors thank Cyril Varghese, Eugene Muchnik, and Anna Shapiro for their assistance in chart reviews.

\section{References}

1. Tjaden P, Thoennes N. Extent, nature, and consequences of intimate partner violence: findings from the National Violence against Women Survey. Washington, D.C.: US Department of Justice, 2000. p. iii.

2. Muelleman RL, Lenaghan PA, Pakieser RA. Battered women: injury locations and types. Ann Emerg Med 1996;28:486-92.

3. Coker AL, Smith PH, Bethea L, King MR, McKeown RE. Physical health consequences of physical and psychological intimate partner violence. Arch Fam Med 2000;9:451-7.

4. Martin SL, Matza LS, Kupper LL, Thomas JC, Daly M, Cloutier S. Domestic violence and sexually transmitted diseases: the experience of prenatal care patients. Public Health Rep 1999;114:262-8.

5. Vos T, Astbury J, Piers LS, et al. Measuring the impact of intimate partner violence on the health of women in Victoria, Australia. Bull World Health Organ 2006;84:739-44.

6. Violence by intimate partners. In: Krug EG, et al. (editors). World report on violence and health. Geneva: World Health Organization; 2002.
7. Heise L, Garcia-Moreno C. Violence by intimate partners. Chapter 4. In: Krug EG, Dahlberg LL, Mercy JA, Zwi AB, Lozano R, editors. World report on violence and health. Geneva: World Health Organization; 2002. p. 89-121.

8. Greenfeld LA, Rand MR, Craven D, et al. Violence by intimates: analysis of data on crimes by current or former spouses, boyfriends, and girlfriends. Washington, D.C.: US Department of Justice; 1998.

9. Warshaw C, Ganley AL. Improving the health care response to domestic violence: a resource manual for health care providers. San Francisco: Family Violence Prevention Fund; 1996.

10. Wisner CL, Gilmer TP, Saltzman LE, Zink TM. Intimate partner violence against women: do victims cost health plans more? J Fam Pract 1999;48:43943.

11. Coker AL, Hopenhayn C, DeSimone CP, Bush HM, Crofford L. Violence against women raises risk of cervical cancer. J Womens Health (Larchmt) 2009; 18:1179-85.

12. Coker AL, Sanderson M, Fadden MK, Pirisi L. Intimate partner violence and cervical neoplasia. J Womens Health Gend Based Med 2000;9:1015-23.

13. Loxton D, Powers J, Schofield M, Hussain R, Hosking $\mathrm{S}$. Inadequate cervical cancer screening among mid-aged Australian women who have experienced partner violence. Prev Med 2009;48:184-8.

14. Lemon SC, Verhoek-Oftedahl W, Donnelly EF. Preventive healthcare use, smoking, and alcohol use among Rhode Island women experiencing intimate partner violence. J Womens Health Gend Based Med 2002;11:555-62.

15. Cronholm PF, Bowman MA. Women with safety concerns report fewer gender-specific preventive healthcare services. J Womens Health (Larchmt) 2009: Epub ahead of print.

16. Hathaway JE, Mucci LA, Silverman JG, Brooks DR, Mathews R, Pavlos CA. Health status and health care use of Massachusetts women reporting partner abuse. Am J Prev Med 2000;19:302-7.

17. Modesitt SC, Gambrell AC, Cottrill HM, et al. Adverse impact of a history of violence for women with breast, cervical, endometrial, or ovarian cancer. Obstet Gynecol 2006;107:1330-6.

18. Moy B, Park ER, Feibelmann S, Chiang S, Weissman JS. Barriers to repeat mammography: cultural perspectives of African-American, Asian, and Hispanic women. Psychooncology 2006;15:623-34.

19. Ferrante JM, Chen PH, Crabtree BF, Wartenberg D. Cancer screening in women: body mass index and adherence to physician recommendations. Am J Prev Med 2007;32:525-31.

20. Ferrante JM, Chen PH, Jacobs A. Breast and cervical cancer screening in obese minority women. J Womens Health (Larchmt) 2006;15:531-41.

21. Schmidt NK, Woods TE, Stewart JA. Domestic violence against women with cancer: examples and 
review of the literature. J Support Oncol 2006;4: 24-8, 33.

22. Bowman JA, Sanson-Fisher R, Redman S. The accuracy of self-reported Pap smear utilisation. Soc Sci Med 1997;44:969-76.

23. Canfell K, Beral V, Green J, Cameron R, Baker K, Brown A. The agreement between self-reported cervical smear abnormalities and screening programme records. J Med Screen 2006;13:72-5.

24. Gordon NP, Hiatt RA, Lampert DI. Concordance of self-reported data and medical record audit for six cancer screening procedures. J Natl Cancer Inst 1993;85:566-70.

25. Ferrante JM, Ohman-Strickland P, Hahn KA, et al. Self-report versus medical records for assessing cancer-preventive services delivery. Cancer Epidemiol Biomarkers Prev 2008;17:2987-94.

26. Chen PH, Rovi S, Washington J, et al. Randomized comparison of 3 methods to screen for domestic violence in family practice. Ann Fam Med 2007;5: 430-5.

27. American Cancer Society. Cancer facts and figures. Atlanta: American Cancer Society; 2008.

28. Chen PH, Rovi S, Vega M, Jacobs A, Johnson MS. Screening for domestic violence in a predominantly Hispanic clinical setting. Fam Pract 2005;22:617-23.

29. Chen PH, Rovi S, Vega M, Jacobs A, Johnson MS. Relation of domestic violence to physical and mental health among Hispanic women. J Health Care Poor Underserved 2009;20:569-82.

30. Sherin KM, Sinacore JM, Li XQ, Zitter RE, Shakil A. HITS: a short domestic violence screening tool for use in a family practice setting. Fam Med 1998; 30:508-12.

31. White HR, Chen PH. Problem drinking and intimate partner violence. J Stud Alcohol 2002;63:20514.

32. Charlson ME, Pompei P, Ales KL, MacKenzie CR. A new method of classifying prognostic comorbidity in longitudinal studies: development and validation. J Chronic Dis 1987;40:373-83.

33. Deyo RA, Cherkin DC, Ciol MA. Adapting a clinical comorbidity index for use with ICD-9-CM administrative databases. J Clin Epidemiol 1992;45:613-9.

34. Moineddin R, Matheson FI, Glazier RH. A simulation study of sample size for multilevel logistic regression models. BMC Med Res Methodol 2007;7: 34.

35. Brown JB, Lent B, Schmidt G, Sas G. Application of the Woman Abuse Screening Tool (WAST) and WAST-short in the family practice setting. J Fam Pract 2000;49:896-903.

36. Martino MA, Balar A, Cragun JM, Hoffman MS. Delay in treatment of invasive cervical cancer due to intimate partner violence. Gynecol Oncol 2005;99: 507-9.

37. Farley M, Golding JM, Minkoff JR. Is a history of trauma associated with a reduced likelihood of cervical cancer screening? J Fam Pract 2002;51:827-31.

38. McFarlane J, Malecha A, Watson $\mathrm{K}$, et al. Intimate partner sexual assault against women: frequency, health consequences, and treatment outcomes. Obstet Gynecol 2005;105:99-108.

39. Agency for Healthcare Research and Quality, US Department of Health and Human Services. Screening for breast cancer. Available at http://www. ahrq.gov/clinic/uspstf/uspsbrca.htm. Accessed 20 March 2010.

40. American Medical Association diagnostic and treatment guidelines on domestic violence. Arch Fam Med 1992;1:39-47.

41. Family violence: an AAFP white paper. The AAFP Commission on Special Issues and Clinical Interests. Am Fam Physician 1994;50:1636-40, 1644-6.

42. ACOG technical bulletin. Domestic violence. Number 209-August 1995 (replaces no. 124, January 1989). American College of Obstetricians and Gynecologists. Int J Gynaecol Obstet 1995;51:161-70. 